\title{
CATALYSIS: CLOSING THE MOLECULAR AND MACROSCOPIC SCIENCES GAP
}

\author{
R. A. VAN SANTEN \\ Schuit Institute of Catalysis, Eindhoven, University of Technology, The Netherlands
}

(Received 1 July 1995)

\begin{abstract}
Progress in catalysis is described as the result of the interplay between societal demands and autonomous scientific developments. A short historic review of the succession of new catalytic processes that took place in the course of this century is given. Also the development of catalysis as a scientific discipline is sketched. Three branches of catalysis are distinguished. Physical chemistry developing into catalytic reaction engineering, kinetics and catalyst characterization, inorganic chemistry as a basis to catalyst preparation and coordination chemistry leading to organometallic chemistry and homogeneous catalysis. It is shown how catalysis science changes from a descriptive science, focusing on structure-performance relations to a predictive science, with a basis in molecular mechanistic understanding. Major modern concepts in fundamental catalysis are discussed. The paper is concluded with an outline of trends in the different scientific catalytic disciplines. The need to integrate disciplinary approaches into system approaches is pointed out.
\end{abstract}

\section{INTRODUCTION}

It is now nearly a century after the origin of industrial catalysis based on scientific innovation and process research. An understanding of the developments that led to catalysis as we know it today may be useful for an evaluation of future perspectives. Two important factors led to the ammonia synthesis process [1], generally to be considered the beginning of industrial catalysis. Of major political influence was the general recognition that the use of nitrogen from air for the production of nitrates would be of significant benefit. Secondly, the scientific formulation of chemical thermodynamics and the chemical rate equation provided a basis for the large-scale empirical catalyst search program that finally led to the corresponding industrial process.

A major driving force to process innovation and the search for new chemical reactions is the changing need for use of different raw materials, the desire to produce new products or the need for processes that are selective and energy efficient. The call for environmentally beneficial catalysis is an example of the latter.

After the invention of the ammonia synthesis process, catalysis as an industrial and scientific activity developed rapidly. As we will sketch in the next section many new industrially important processes followed. Initially, those processes were mainly coal based, later processes used oil as a raw material. Practical catalysis remained and still is largely a highly empirical activity. The early period led to many breakthroughs in physical chemistry, some of them recognized with Nobel prizes (Table 1). Engineering requirements demand kinetic models for reactor design. This need in combination with the rapidly increasing general understanding of kinetics created kinetics as a catalytic subdiscipline. Kinetic equations of catalytic reactions were based on the proposed reaction mechanisms [2]. The parameters required were usually obtained by fitting to the experiment. This established a long tradition in catalysis research to search for catalyst performance-structure relations. It gave rise to a need for catalyst characterization.

The history of catalyst characterization consists, in essence, of the successive introduction of new techniques enabling to study the catalyst, initially on a mesoscopic level and finally in atomistic detail [3]. The advanced capabilities of sophisticated spectroscopic techniques have been especially essential for the dramatic progress of the past 25 years. An early non-spectroscopic breakthrough was the development of the Brunauer-Emmett-Teller [4] method, that applies physical adsorption for the determination of the surface area and morphology of the catalyst. It led to techniques to analyze the pore-size distribution of heterogeneous catalysts. Selective chemisorption, that discriminates between surface atoms, was used later to probe the relative amounts of different reactive surface phases. Methods were soon complemented by X-ray diffraction and electron microscopy.

The chemical basis of catalytic reactivity long remained limited to reactivity correlations with catalyst structure parameters, rather than to depend on direct information of the reaction intermediates and their transformations on the working catalyst. The main difficulty, of course, being the need to obtain atomistic information on the structure of the catalytically active surface of a catalyst at working conditions. Therefore, the major importance in the formulation of a molecular basis to surface-chemical reactivity has been the study of well-defined surfaces at well-defined conditions. Its disciplinary tradition starts with Langmuir [5], working with vacuum tubes on problems basic to electronic engineering. It developed into a school 
Table 1. Nobel prizes

\begin{tabular}{lll}
\hline 1901 & J.H. van"t Hoff & Physical chemistry \\
1903 & S.A. Arrhenius & Physical chemistry \\
1909 & W.F. Ostwald & Catalysis, reaction rates \\
1912 & P. Sabatier & Catalytic hydrogenation \\
1919 & F. Haber & Ammonia synthesis \\
1920 & W.H. Nernst & Physical chemistry \\
1931 & C.R. Bergius, C. Bosch & Chemical engineering \\
1932 & I. Langmuir & Surface chemistry \\
1956 & C.N. Hinshelwood, N.N. Semenov & Chemical kinetics \\
1963 & K.W. Ziegler, G. Natta & Polymerization catalysis \\
1967 & M. Eigen, R.G.W. Norrish, G. Porter & Kinetics, flash photolysis \\
1968 & L. Onsager & Irreversible thermodynamics (linear) \\
1973 & E.O. Fischer, G. Wilkinson & Organometallic chemistry \\
1977 & I. Prigogine & Irreversible thermodynamics (nonlinear) \\
1986 & D.R. Herschbach, Y.T. Lee, J.C. Polanyi & Reaction dynamics \\
1992 & R.A. Marcus & Electron transfer reactions \\
1994 & G. Olah & Super acidity \\
\hline
\end{tabular}

to study chemisorption on well-defined surfaces. Currently, the use of single crystal surfaces, as models of the catalytically active surface, can be considered key to the present molecular understanding of catalytically reactive surfaces. Crucial was Somorjai's [6] approach to combine the study of ad-layer crystallography with catalytic activity studies on the same systems.

The work of Ertl [7], mapping the dynamics of surface structural changes during the catalytic reaction, provides a major new perspective on the basis of catalytic kinetics. Another approach to the molecular description of heterogeneous catalysis has been the study of zeolite catalysts [8]. These materials, widely used as solid acid catalysts, have micropores whose structure is crystallographically well defined. This enables the application of bulk spectroscopies to characterize the catalytically active materials and deduce information on the catalytically reactive sites.

These experimental developments have also provided new incentives to theory. Applied quantumchemical studies provide a quantum-chemical basis to surface-chemical reactivity [9]. Statistical approaches $[10]$ as Monte Carlo techniques are used to study the surface layer properties that underlay the working of the heterogeneous catalyst. Fortunately, the state of the art of computer hardware and first principle electronic structure calculations are such that in case of disagreement between experimental and computed results, one often has to question primarily the validity of the chemical model chosen to interpret the experiment.

We will highlight the evolving concepts on molecular surface reactivity in Section 3.

It appears that the new and improved molecular insights not only bridge a long-standing gap with traditionally molecular disciplines as organic chemistry, but also provide the basis to a new approach in kinetic modelling of immediate relevance to catalytic chemical engineering. The atomistic and molecular approaches lead to predictions of values of para- meters that previously were only accessible to the chemical engineer by empirical fitting to experiment.

Catalytic kinetics can be considered as a branch of physical chemistry. One of its founders, Ostwald, gave catalysis its modern definition: A catalyst affects the rate of a reaction and cannot change the equilibrium between reactants and products. A different catalysis sub-discipline has been established by Sabatier [11] and Ipatieff [12]. At the same time that ammonia synthesis was discovered, Sabatier studied hydrogenation catalysts. He followed earlier ideas by Faraday [13] and considered catalysis as the result of the formation and transformation of surface intermediates. This very fruitful idea developed into a catalytic principle that predicts that an optimum reactant-catalyst interaction exists for which the reaction rate reaches a maximum. The interaction should not be too weak so that surface complex formation will not occur and not too strong, which would prevent desorption of reaction products. Balandin's volcano curve [14] and many later volcano curves that are found when the overall reaction rate of a catalytic reaction is plotted against adsorption energy are a consequence of Sabatier's rule.

Sabatier and Ipatieff, who were one of the first to discuss the role of promotors in catalysis, were chemists with the primary goal to develop catalytic materials for organic reactions. The development of catalysts can be considered to be the realm of applied inorganic chemistry and the search for new reactions, the realm of applied organic chemistry.

Ipatieff and his school provided many acid-based catalytic reactions that are currently applied in the petrochemical industry.

At present a true molecular basis in the synthesis of heterogeneous catalysts is developing amongst others due to cross fertilization with organo-metallic chemistry. Catalysis in the homogeneous phase with coordination complexes as in the Wacker reaction [15], or using carbonyl complexes as in Reppe's chemistry [16a] has developed into the discipline of 


\section{Catalytic Science}

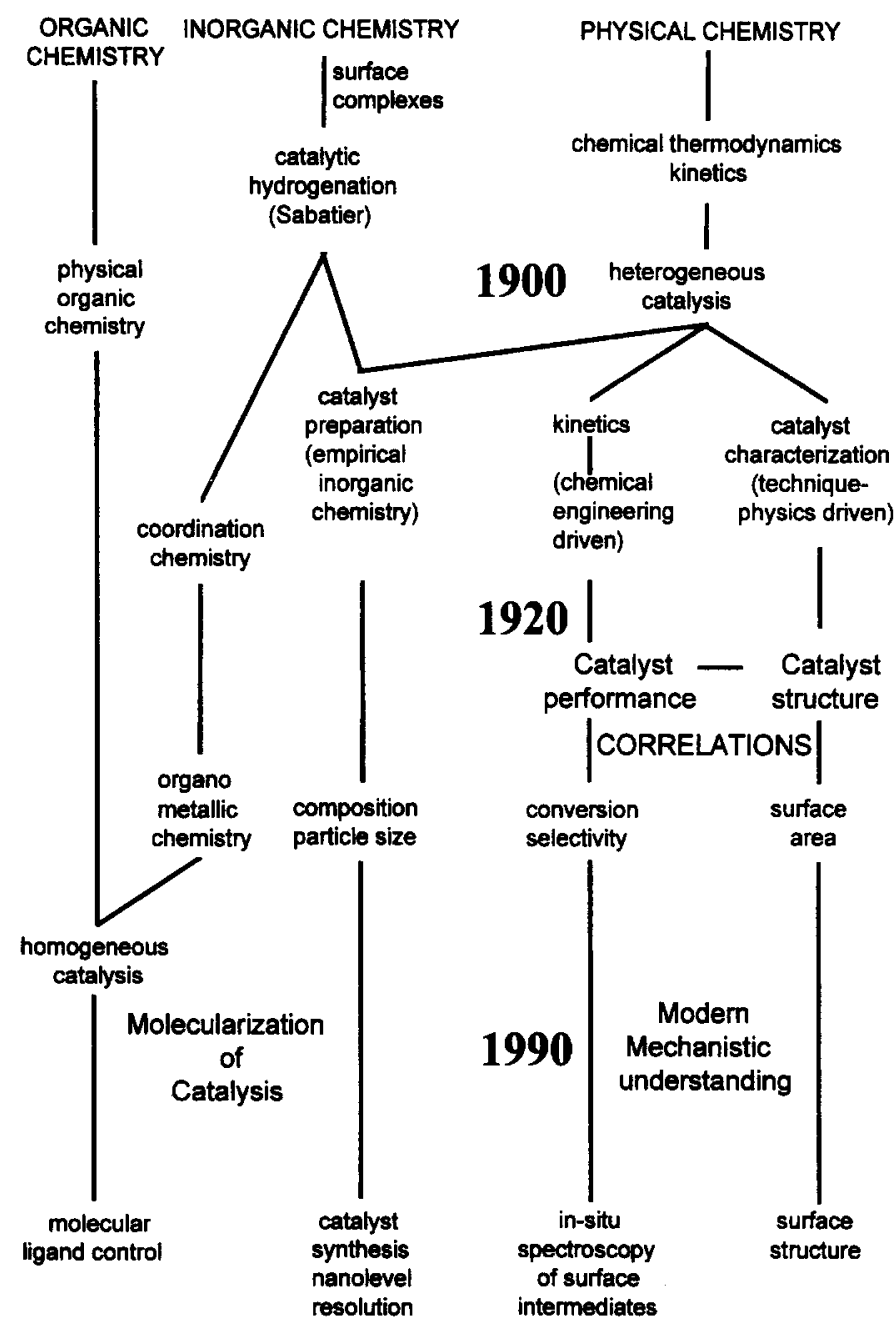

Fig. 1. Scheme of development of the catalytic disciplines.

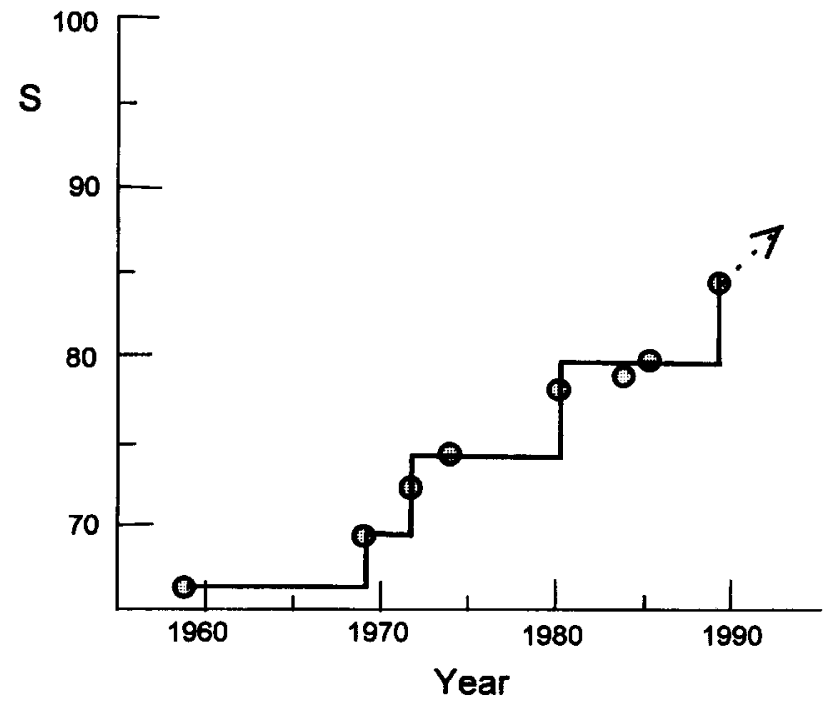

Fig. 2. Chronology of ethylene epoxide catalyst improvement. 
organo-metallic chemistry. It has provided us with many new homogeneous catalytic systems.

Organometallic complexes, when used as catalysts, provide means for molecular manipulation by choice of complexing ligands. Chiral ligands enable the synthesis of chiral compounds, as L-DOPA produced by asymetric hydrogenation of cinnamic acid [16b]. Recently, this has led to a new generation of polymerization catalysis [17]. It creates an additional promise for improved enantio-selective catalysis. Organometallic complexes and clusters can also be used as precursor reagents to produce catalytically active sites on the surfaces of catalyst supports or within the cavities of zeolites. With control of the successive catalyst transformation reactions that lead to the active catalyst phase, it provides a molecularly controlled synthetic path of catalysts.

A schematic overview of the developments of catalytic science subdisciplines is given in Fig. 1.

In the next section we will summarize chronologically the main catalyst systems and processes that have been introduced during the past hundred years. It will provide an opportunity to indicate the ongoing innovation of catalytic processes that continues up to the present. Of course, discovery of new reactions and new catalysts is usually serendipitous. The impact of scientific understanding is reflected in the rate that the new finding can be implemented as a new process and is improved by consecutive research. For instance, mechanistic understanding of the ammonia synthesis catalyst has led to a new class of improved catalysts. Many classical processes operate with significantly improved activity or selectivity compared to the processes based on the original catalyst formulations. An illustration is provided for by Fig. 2 that illustrates the improvement of the ethylene epoxidation selectivity in the silver-catalyzed process as a function of time. New catalyst formulations provided the basis to improvement.

In Section 3, mainly the current status of the molecular basis of heterogeneous catalysis will be reviewed. The aim is not only to provide an indication of our current understanding of catalytic reactivity, but also to formulate important yet outstanding questions.

In a final section we will summarize the main catalytic research approaches that can be foreseen in the near future and how they relate to present societal needs.

\section{HISTORY OF CATALYTIC PROCESSES}

According to Quadbeck-Seeger [18] a criterium to distinguish mature areas of science or technology is whether research is driven by technological needs for improvement or whether technological changes are driven by autonomous scientific discoveries. Clearly, market pull as well as science push alternate or sometimes occur parallel in catalytic technology. The existing conversion reactions can become revolutionized by the discovery of new catalytic materials, sometimes requiring new reactor engineering and with the poten- tial to yield dramatic improvements in conversion yields. The introduction of zeolites as solid acid catalysts can be considered as an example of such an event in the catalytic cracking process.

Research finally leading to major new catalytic conversion reactions has sometimes been directed by widely understood implicit missions. The development of the ammonia synthesis process mentioned before, as well as the Ostwald process for the oxidative conversion of ammonia to nitrate clearly served a practical purpose. It also led to scientific innovations recognized by Nobel prizes. The ammonia synthesis process was the first of many new hydrogenation processes that would follow. Earlier industrial processes, as sulfuric acid production were mainly oxidation processes. The ammonia synthesis process demonstrated a general strength of heterogeneous catalytic processes. Such processes can be run as continuous processes. Separation of catalyst from product already occurs in the reactor.

Also the coal conversion effort directed by Fischer, amongst others leading to the Fischer-Tropsch process [19], created the incentive for unforeseen scientific innovation. The coordination catalysts discovered later in the same laboratory leading to low-pressure polymerization processes [20], were the spin-off of explorative research for olefin conversion reactions.

Next to a new catalytic reaction, the introduction of new catalytic materials is an indicator of fundamental innovation in catalysis. The actual process application may depend on particular societal conditions.

The main catalysts used initially were promoted metallic catalysts, variations of the ammonia synthesis catalyst, based on alkali and earth alkali promoted iron. The Fischer-Tropsch catalyst applied to convert synthesis gas to higher hydrocarbons had nearly the same composition. The related methanol catalyst initially was based on $\mathrm{Cr}_{2} \mathrm{O}_{3} / \mathrm{ZnO}$, as was the water gas shift catalyst applied in the ammonia synthesis process to provide hydrogen.

Later the hydrogenating components $\mathrm{Cr}_{2} \mathrm{O}_{3}$ became replaced by $\mathrm{Cu}$. It resulted in an improved methanol synthesis process that could operate at lower pressures. Nickel can be applied to hydrogenate unsaturated bonds in fatty oils. It is used to prepare margarine from animal fat.

Related catalysts based on $\mathrm{Co}, \mathrm{Ni}$ and Mo were developed for the dehydrosulfurization of coal liquids. Under the influence of $\mathrm{H}_{2} \mathrm{~S}$ the catalysts are converted to the sulfides. In related processes sulfidic catalysts are used up to the present day, with one important major difference. Whereas the initial catalysts usually were metallic fused catalysts or co-precipitated oxides or sulfides of low surface area, most of the modern catalysts are high surface area catalysts with the active catalyst phase distributed over a high surface area inert support.

The next important class of catalysts are homogeneous and heterogeneous amorphous acidic catalysts. They are due to inventions driven by the desire to convert heavy oil fractions to lighter more useful oil 
products, or by the desire to upgrade light gases, generated by cracking processes, to more heavy and more useful product molecules. The chemistry involved proceeds mechanistically via nonclassical carbocations [21]. The discovery of their existence using superacid catalysis has lead to Olah's 1994 Nobel prize for chemistry. The cracking and alkylation processes introduced around 1940 are still applied on a wide scale, but significantly improved again due to several new catalyst developments. A breakthrough in the oil industry was the introduction of a bifunctional acidic catalyst, with a noble metal as Pt instead of $\mathrm{Cr}_{2} \mathrm{O}_{3}$ as the active hydrogenation component. Due to its introduction in the refineries the selective conversion of paraffins to gasoline in the catalytic reforming process was significantly improved. The next major improvement occurred with the introduction of zeolites as solid acid catalysts in the end of 1960s [8]. It led to many previously unknown conversion reactions. Some of them are currently applied in major petrochemical processes.

Two additional crucial parallel catalyst developments have to be mentioned. Forty years ago the chemical industry became a large scale producer for polymers. For this it not only needed processes to convert monomers to polymers, but also processes to produce efficiently the monomer intermediates. This led, for instance, to a new class of heterogeneous mixed oxide catalysts to produce acrylonitrile as well as acrolein [22]. A representative example is the $\mathrm{Bi}_{2} \mathrm{O}_{3} / \mathrm{MoO}_{3}$ system.

In the homogeneous phase selective catalytic oxidation processes were developed to produce acetaldehyde and vinyl acetate using coordination complexes with $\mathrm{Pd}^{2+}$. A unique heterogeneous catalyst to produce ethylene epoxide was found in the form of $\mathrm{Ag}$ dispersed on an alumina support. Whereas the initial selectivity of this catalyst when invented in 1936 was around $30 \%$, later improvements have led to a current selectivity of around $90 \%$ [23].

Homogeneous metal complexes had already been used by Reppe [16a] for carbonylation reactions of ethylene and acetylene. They precede the later organometallic complexes, that now are used in nearly $40 \%$ of the current larger-scale chemical processes, due to major process innovations especially in the 1970s. An outstanding example is the Rh-catalysed synthesis of acetic acid from synthesis gas [24].

The Ziegler-Natta process for the large-scale production of polypropylene and ethylene developed in the middle of this century was based on the catalytic action of $\mathrm{TiCl}_{3}$, later dispersed on a $\mathrm{MgCl}_{2}$ support [20]. This heterogeneous catalyst can be considered as a representative of an immobilized coordination complex. Recently, a completely new class of homogeneous catalysts has been introduced, based on $\mathrm{Ti}^{4+}$ and $\mathrm{Zr}^{4+}$ containing organometallic complexes, with tunable organic ligands enabling synthesis of stereoregular polymers of high quality [17]. This implies the actual introduction of molecularly designed catalysts into large-scale catalytic processes.
Many of the catalytic systems mentioned so far are still used in current processes, often improved by changes in catalyst composition or adapted to new processing requirements. An example of the latter is the phosphorus-vanadate catalyst for the oxidation of butane to maleic acid as a replacement of processes using aromatics as feedstock.

Environmental catalysis for processes that reduce emission of molecules as $\mathrm{SO}_{2}$ or $\mathrm{NO}$ is now widely applied. Catalysts for automotive exhaust treatment [25a] are bi- or tri-metallic, able to reduce $\mathrm{NO}$ by $\mathrm{CO}$. As support ceramic Honeycomb-type materials are often used, to prevent pressure buildup in the reactor. These noble-metal-based catalysts cannot be operated in excess oxygen. With ammonia NO can be reduced in excess oxygen [25b]. In stack gas a catalyst consisting of $\mathrm{V}_{2} \mathrm{O}_{5}$ coated on $\mathrm{TiO}_{2}$ can be used. Recently, metal-cation-activated zeolites have been proposed that can decompose NO at higher temperature, or reduce NO with light organic molecules in the presence of oxygen [26].

Also alternative processes to reduce salt in effluents are needed. A classical success is the catalytic production of ethylene epoxide. This replaces the classical route via epichlorhydrine coproducing $\mathrm{CaCl}_{2}$ from $\mathrm{Cl}_{2}$ [23].

Zeolites with elements as $\mathrm{Ti}$, Co or $\mathrm{V}$ substituting for lattice $\mathrm{Si}$ have been found to be new selective oxidation catalysts [27]. Recently, a Ti-based catalyst has been introduced to produce catechol from phenol using hydrogen peroxide as a cooxidant. Related catalysts have been proposed for the synthesis of caprolactam without coproduction of ammoniumsulfate.

To replace chlorofluorocarbons (CFC) new Lewis acid catalyzed processes have been developed to produce chlorine-free refrigeration chemicals [28]. A historic summary of catalytic processes is given in Fig. 3.

\section{CONCEPTS IN FUNDAMENTAL CATALYSIS}

The use of catalytic model systems, application of spectroscopic techniques and computational studies have created a new sometimes unexpected view on the molecular basis of the working of the active catalyst system. The essence of catalysis is the concept of the catalytic reaction cycle, which we have already discussed in the context of Sabatier's principle. Knowledge on reaction intermediates, their transformations and the nature of the reactive catalyst center determines our level of molecular understanding of catalysis. The now classical homogeneous Wilkinson catalyst [29] can serve to illustrate the catalytic reaction cycle (Fig. 4). The reaction catalyzed is the hydrogenation of an olefin by an organometallic complex of $\mathrm{Rh}$. The $\mathrm{Rh}$ complex can react with an incoming $\mathrm{H}_{2}$ or olefin molecule once a vacancy is created around the octahedrally coordinated $\mathrm{Rh}$ center. The important consecutive steps that then occur are oxidative addition of hydrogen and adsorption of olefin molecule, recombination and desorption of the 


\begin{tabular}{|c|c|c|}
\hline - 1910 & $\begin{array}{l}\text { - coal conversion } \\
\text { - hydrogenation }\end{array}$ & $\begin{array}{l}\text { - desulfurization } \\
\text { - gynthetic gasoline } \\
\text { - methanol } \\
\text { - fat hardening } \\
\text { - ammonia synthesis }\end{array}$ \\
\hline $\begin{array}{l}-1930 \\
\text { automobiles }\end{array}$ & - catalytic cracking & $\begin{array}{l}\text { - acidic materials } \\
\text { - riser-downer } \\
\text { technology }\end{array}$ \\
\hline $\begin{array}{l}1940 \\
\text { World War II }\end{array}$ & $\begin{array}{l}\text { - synthetic kerosine } \\
\text { - synthetic rubber }\end{array}$ & $\begin{array}{l}\text { - new acid catalysis } \\
\text { - anionic catalysis }\end{array}$ \\
\hline 1950 & & \\
\hline $\begin{array}{l}\text { petrochemical } \\
\text { industry }\end{array}$ & $\begin{array}{l}\text { - polymers } \\
\text { - intermediates } \\
\text { - catalytic reforming }\end{array}$ & $\begin{array}{l}\text { - coordination catalysis } \\
\text { - reducible oxidic catalysts } \\
\text { - bifunctional catalysis } \\
\text { - zeolites }\end{array}$ \\
\hline \multirow[t]{3}{*}{$\begin{array}{l}1970 \\
\text { energy crisis }\end{array}$} & $\begin{array}{l}\text { - coal } \\
\text { gasoline }\end{array}$ & $\begin{array}{l}\text { - new catalytic processes } \\
\text { (zeolites) }\end{array}$ \\
\hline & chemicals & \\
\hline & - gas & - homogeneous catalysis \\
\hline \multirow{3}{*}{$\begin{array}{l}\text { - } 1980 \\
\text { environment }\end{array}$} & - automotive exhaust & - computer control, sensors \\
\hline & $\begin{array}{l}\text { - fine chemicals } \\
\text { catalysis }\end{array}$ & $\begin{array}{l}\text { - enantiomeric synthesis } \\
\text { - molocular heterogeneous } \\
\text { catalysis } \\
\text { - catalytic organic chemistry }\end{array}$ \\
\hline & - polymers & - homogeneous catalysts \\
\hline
\end{tabular}

Fig. 3. History of catalytic process innovation.

product by reductive elimination. The catalytically active state of the complex that is regenerated after each reaction cycle is different from the starting material, namely the hydrogen containing complex. This illustrates the general phenomenon that the catalytically active center is often generated during the catalytic reaction. Hence, Berzelius definition of a catalyst, as a material that does not change by a reaction, is not strictly true. Only the catalytically active phase is regenerated after each reaction cycle.

The classical picture of catalysis by a surface has been provided by Langmuir [5]. He proposed a surface with a finite number of equal vacant sites. Adsorbates are supposed not to interact. For the dependence of the surface coverage on gas pressure $p$ he deduced the adsorption isotherm:

$$
\frac{\theta}{1-\theta}=K p
$$

that has been named after him. $\theta$ is the site occupation and $K$ the equilibrium constant. This expression is identical to the Michaelis-Menten expression applied in homogeneous catalysis for the fraction of reacted complexes.

Surface scientific investigation and recently especially STM-studies have convincingly demonstrated that the reality of the reactive surface is significantly more complex [36]. Generally, the interaction between adsorbates cannot be ignored. Lateral interactions may lead to nonideal mixing behavior of adsorbed layers. Surface adsorbate layers are often present as ordered structures forming islands. This implies that the Langmuir adsorption term (1) has to be replaced by an expression as [10a]

$$
\frac{\theta-x}{1-\theta-x}=K p
$$

where $x$ is a complex function of coverage and adsorbate lateral interaction energy.

The ordering of adsorbates on a surface will strongly affect the rate of surface processes. For instance, the rate of dissociative adsorption for an ideal mixing surface layer will be $\sim(1-\theta)^{2}$, whereas when repulsive lateral interactions are strong the adsorption rate is $\sim(1-2 \theta)$. An adsorbed atom or molecule has an increased interaction when the coordination of surface atoms with neighboring surface atoms is decreased. This can provide a driving force to surface atom rearrangements with important consequences to catalysis.

At low surface coverage an adsorbed atom will usually not disrupt the surface lattice, but pull surface atoms outwards of the surface to form a surface complex embedded in the metal surface [31] Adsorbates tend to form chemisorption complexes that are geometrically close to the analogous coordination complexes. The local surface structural change is counteracted by surface stress forces that respond to the local surface strain of the adsorption site.

When more atoms absorb surface stress can be released by rearrangement of surface atoms [32], which will create sites that have a stronger interaction with the adsorbate. This may lead to the formation of ordered overlayers with transport of surface atoms. During the catalytic reaction cycle such sites may be formed and consecutively destroyed. Facetting of surfaces to give surface phases in reaction may occur after an initial period [33]. The relative stabilities of surface phases are a strong function of surface coverage and composition that can be strongly reactioncondition-dependent. Under particular conditions the changes in surface phases can be made to oscillate which leads to fascinating spatial-temporal patterns [7].

The microscopic picture that evolves is a dynamic one. The time scale of a catalytic event is typical a microsecond or larger. However, surface atoms will locally rearrange on a picosecond time scale, the same time scale at which adsorbate molecules will equilibrate to the surface. On a time scale varying between a nanosecond and a microsecond, surface diffusion and surface reaction events can take place.

The presence of lateral interactions between atoms adsorbed in the surface layer can also have an important consequence in the selectivity of a reaction. The chemical reactivity of adsorbated atoms may change as a function of surface concentration and composition. For instance, the selectivity of the epoxidation reaction of ethylene by oxygen appears to be strongly 

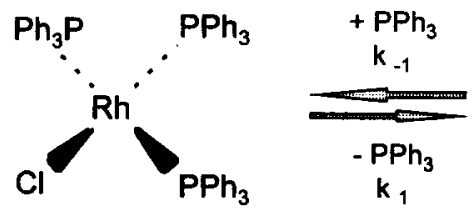<smiles>Cl[Pb]([Pb])([Pb])[PbH]</smiles>

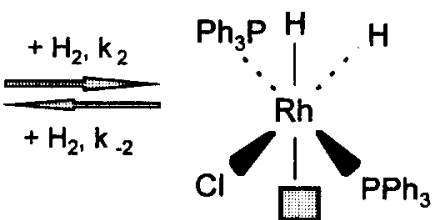<smiles>CCCC1CCCC1CC</smiles>

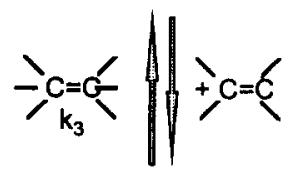
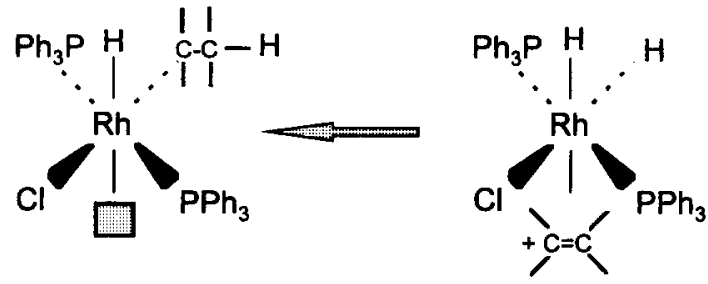

Fig. 4. The catalytic reaction cycle of Wilkinson's hydrogenation catalyst.

dependent on the composition of the surface oxygen layer present on the silver catalyst [23]. At high oxygen surface coverage selective conversion of ethylene to the epoxide occurs. The surface layer then has a stoichiometric composition of $\mathrm{AgO}$, with part of the oxygen atoms located in a subsurface layer and other oxygen atoms adsorbed in the external surface layer. The nature of the adsorbed oxygen atoms is electrophilic and favorable for insertion into the $\pi$-bond of ethylene. At low surface coverage the adsorbed oxygen atoms are Lewis basic in nature and assist $\mathrm{CH}$ bond cleavage. The change in reactivity of adsorbed atoms with coverage is a direct consequence of lateral interactions mediated by the changed valency of silver with surface coverage.

Another example is provided for by the chain growth reaction in Fischer-Tropsch catalysis. It has now been extensively demonstrated that dissociation of adsorbed $\mathrm{CO}$ is a necessity [33] and that the reactivity of the adsorbed carbon atoms is a strong function of coverage [35]. Whereas carbon atoms present at low coverage $\left(\mathrm{C}_{x}\right)$ are highly reactive when activated by coadsorbed hydrogen, carbon atoms adsorbed at higher coverage $\left(\mathrm{C}_{\beta}\right)$ show a reduced activity. The $\mathrm{C}_{\alpha}$ atoms lead to formation of higher hydrocarbons [35].

Surface investigations with single crystal surfaces covered with carbon atoms have convincingly shown that the formation of carbon overlayers is a strong function of surface concentration [36]. Whereas at low concentration $\mathrm{C}$ atoms are adsorbed as isolated atoms, on $\mathrm{Ni}$ at higher concentration $(\theta>0.2)$ $\mathrm{C}$ atoms adsorb in islands. Surface relaxation and reconstruction (due to lateral interactions) result in a stronger bonding of the carbon atoms to the surface in the carbidic overlayer state than when separate. The $\mathrm{C}_{\alpha}$ species can probably be identified with the isolated $\mathrm{C}$ atoms and the less reactive $\mathrm{C}_{\beta}$ species with the surface carbide overlayer.

For adsorbed oxygen, Roberts [37] has also proposed a difference between the reactivity of isolated oxygen atoms and oxygen atoms that are part of an oxygen overlayer structure. Isolated oxygen atoms adsorbed to a $\mathrm{Cu}\left(\begin{array}{lll}1 & 1 & 1\end{array}\right)$ surface have been found to be highly reactive and to promote dissociative adsorption of $\mathrm{NH}_{3}$. However, oxygen atoms that are part of the oxidic overlayer are found to be nonreactive. $\mathrm{Ob}$ viously, part of this difference has also to be due to the necessity for vacant surface positions to accommodate adsorbed $\mathrm{NH}_{2}$ intermediates.

The two examples cited illustrate changes in surface atom reactivity with coverage. Steric and geometric rearrangements in the surface layer that vary with surface layer composition may also affect the selectivity of a reaction. A well-known case is the selectivity problem of NO reduction by a mixture of $\mathrm{CO}$ and $\mathrm{H}_{2}$ [38].

Catalysis of this reaction by platinum mainly gives $\mathrm{NH}_{3}$, whereas catalysis by $\mathrm{Rh}$ selectively produces $\mathrm{N}_{2}$. The lower reactivity of platinum is indirectly responsible for this. The lower reactivity of platinum gives a relative slow rate of NO dissociation. Therefore, on platinum at steady state the surface coverage of nitrogen atoms will be low. The highly reactive rhodium surface readily dissociates NO. Now at steady state on the rhodium surface atomic nitrogen will be present with a high surface coverage. Hydrogen will always dissociate readily. Because of its low nitrogen coverage on a platinum surface the probability for a nitrogen atom to recombine with a coadsorbed hydrogen atom will be high. It will result in ammonia production. On rhodium the high surface coverage of nitrogen enhances the probability for nitrogen production and hence 
now the selectivity for nitrogen production will be high.

Dissociation of an adsorbed molecule produces molecule fragments adsorbed to the surface. Adsorption of these fragments to the surface is necessary in order to make the dissociation reaction thermodynamically possible. A surface ensemble of several atoms is usually required for dissociation to occur. Reduction paths for dissociation are such that optimum activation of adsorbed molecules occur with large orbital overlap [39a]. Pre-exponents of surface reactions often show low activation entropies in line with the low mobility of the transition state due to the strong interaction of the dissociating molecule with the surface.

When other molecules become coadsorbed the surface concentration of vacant sites will decrease and hence the rate of dissociation will be decreased. Also the adsorption mode of a molecule (and hence its interaction energy) may be strongly affected by coadsorbates. For example, thiophene will adsorb parallel to the metal surface ( $\eta^{4}$ coordination) when adsorbed at low surface coverage, whereas co-adsorption of more thiophene or hydrogen leads to site blocking and forces the thiophene to be adsorbed in perpendicular orientation ( $\eta^{1}$ coordination) [39b].

Even the presence of weakly coadsorbed species may affect the course of the reaction. Iwasawa [40a] has shown that the water gas shift reaction selectivity of $\mathrm{CO}$ with $\mathrm{H}_{2} \mathrm{O}$ depends strongly on the number of $\mathrm{H}_{2} \mathrm{O}$ molecules coadsorbed at the zinc reaction center of a model catalyst. A similar phenomenon appears in the decomposition of formic acid on $\mathrm{TiO}_{2}\left(\begin{array}{ll}1 & 10\end{array}\right)$. Coadsorption of several formic acid molecules changes the selectivity compared to the case of formic acid adsorbed isolated from the others [40b].

The influence of a water layer can dramatically change dissociative chemisorption of a molecule. In an ultra-high vacuum on platinum, methanol will dissociatively adsorb as a methoxy species and hydrogen, and hence form a metal-oxygen bond. From the water phase dissociative adsorption of methanol will primarily occur by $\mathrm{CH}$ cleavage and formation of a metal-carbon bond [41].

We mentioned earlier that dissociative adsorption on a transition metal surface requires a strong interaction with an ensemble of surface atoms. The mechanism of solid acid catalyzed reactions also illustrates the importance of close contact between reactant and catalyst surface atom [42]. We will discuss this for the dissociation of methanol [43]. In microporous solid acidic zeolites the acidic proton is adsorbed to oxygen atoms that bridge a lattice $\mathrm{Si}$ ion, formally in a $4+$ valence state and a lattice ion of lower valency, usually $\mathrm{Al}$, that is formally in $3+$ valence state. To this site methanol can in principle adsorb in two modes, site-on or end-on (see Fig. 5). In the end-on configuration the proton of methanol is bonded to a Lewis basic lattice oxygen atom. The zeolitic proton is directed to the oxygen atom of the methanol molecule. Proton donation to methanol can be considered
Lewis-base-assisted Brønsted acidity. The positive charge that develops on the protonated molecule becomes stabilized by interaction with the negative charges that develop on the oxygen atoms around $\mathrm{Al}$. Dissociation of methanol occurs from its site-on adsorbed position that has a much lower probability for formation. In the transition state the $\mathrm{CO}$ bond stretches, proton donation from the zeolite generates water and a weakly bonded planar $\mathrm{CH}_{3}^{+}$carbenium ion. In the final state the $\mathrm{CH}_{3}^{+}$ion binds to a Lewis basic oxygen atom and forms a methoxy species. The activation energy of the reaction is highly reduced by the strong electrostatic interaction of $\mathrm{CH}_{3}^{+}$and the negatively charged lattice oxygen atom.

As found for other surfaces, again the lattice relaxes during reaction. Proton transfer leads to contraction of surface atom distances. The flexible zeolite lattice will accommodate this relaxation to a large extent. As on metal surfaces again lattice compressibility is an important site-regulating parameter. The high Brønsted acidity of the zeolitic protons bordered to an oxygen atom shared between $\mathrm{Al}^{3+}$ and $\mathrm{Si}^{4+}$ can be considered as Lewis acid $\left(\mathrm{Al}(\mathrm{OR})_{3}\right)$ promotion of the weakly acidic silanol group. Superacidity also occurs when a strong acid as a sulfate becomes Lewis-acidpromoted (Fig. 6). This situation arises on sulfated $\mathrm{ZrO}_{2}$ [44]. Before reaction the sulfate $\mathrm{OH}$ group is hydrogen bonded to the $\mathrm{ZrO}_{2}$ surface. Upon reaction with a basic adsorbate, the free oxygen atom generated on the sulfate becomes stabilized by interaction with the large Lewis acid $\mathrm{Zr}^{4+}$ ion.

Zeolite catalysis can also illustrate the importance of adsorption and diffusion to catalyst activity and selectivity. For a mono-molecular surface reaction, with a rate limiting surface reaction step, the overall rate of a reaction equals

$$
\begin{aligned}
r & =k_{\mathrm{r}} \theta \\
& \approx k_{\mathrm{r}} \frac{K p}{1+K p} .
\end{aligned}
$$

When the reaction is first order, eq. (3b) reduces to:

$$
r=k_{r} K p \text {. }
$$

The overall activation energy now also depends on the heat of adsorption of the molecule. It appears that differences in heat of adsorption may determine to a significant extent the overall rate of acid catalyzed reactions. This is the confinement effect as proposed by Derouane [45].

The finite size of the zeolite cavities can also lead to shape selectivity, due to spatial constraints on the transient states or the slow mobility of large product molecules. Solid acid catalyzed reactions often lead to rapid deactivation. When hydrocarbons are converted, this is due to oligomerization reactions that lead to polyaromatics and carbon formation. Narrow pores of zeolites can suppress the formation of many polyaromates. This is the basis to their longer lifetime in catalytic cracking compared to wide-pore catalysts. For some applications deactivation can be suppressed 
by adding noble metals to the catalyst [46]. Catalysis is now a bifunctional process. The noble metal catalyses hydrogenation of alkenes, intermediates to deactivating oligomerization processes. Practical catalysts often combine catalytic functions to optimize selectivity and stability.

The four important general concepts to catalysis that we discussed are the following.

(a) Self regenerating catalytic cycle: The rate of a reaction is maximum for an optimum interaction strength between reactant and catalyst; dissociative adsorption and desorption compete as rate limiting steps.

(b) Chemisorption: Causes a local electronic and geometric disturbance; lateral interactions may lead to nonideal mixing and site reconstruction.

(c) Site specificity: Dissociation usually requires an ensemble of atoms, selectivity depends on surface topology, surface atom coordination and surface composition. Adsorption complexes have a close resemblance with coordination complexes. Stereo-regio and shape selectivity can be tuned by micropore size, ligand shape and promotors.

(d) Site preparation; phase stability: The catalyst structure adapts to reaction conditions. Catalytic site formation and destruction can be a part of the reaction cycle. Catalyst deactivation may occur by the formation of less-active, thermodynamically stable phases. Deactivation can also occur by poisoning due to coproduct formation or the presence of impurities in the feed [47].

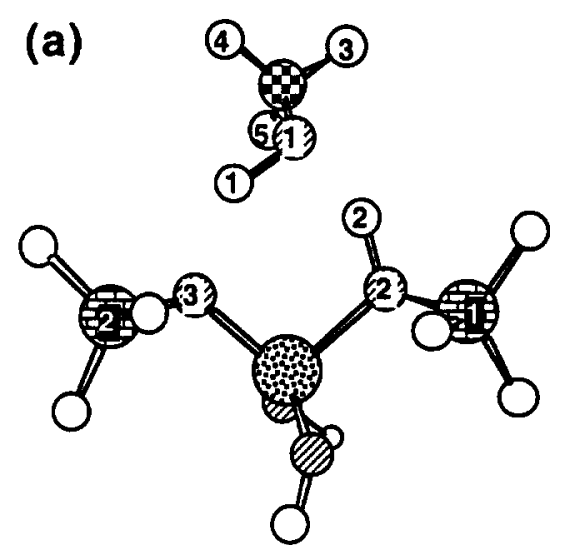

(b)
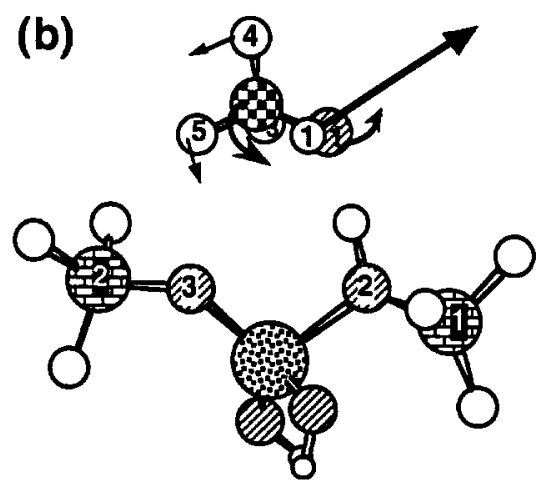

(c)
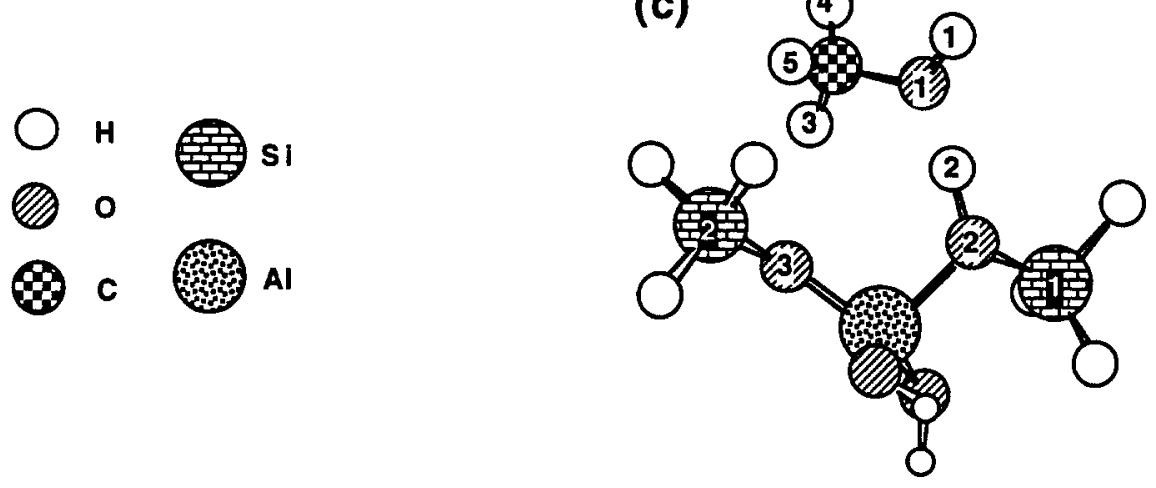

(d)
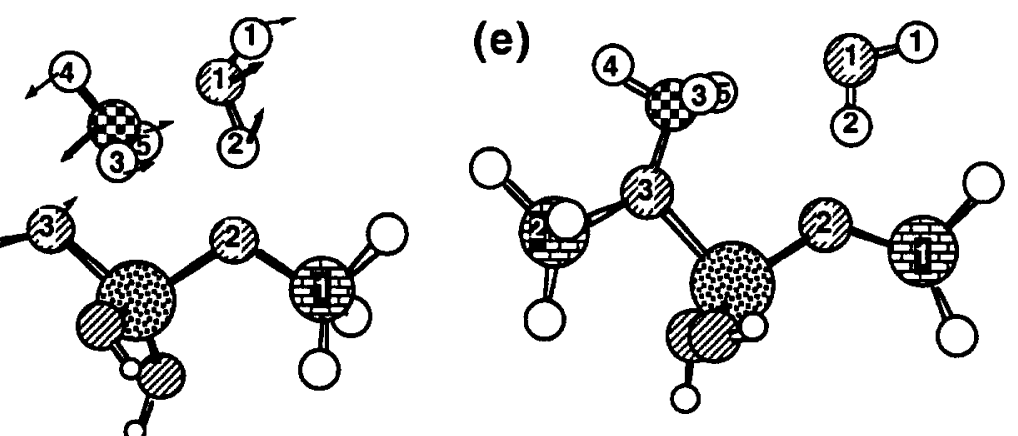

Fig. 5(a). Dehydration of $\mathrm{CH}_{3} \mathrm{OH}$ : "end-on" (a) and "side-on" (c) adsorption complexes; transition state (TS') (b), transition state (TS') (d) and dissociated state (e)[43]. 


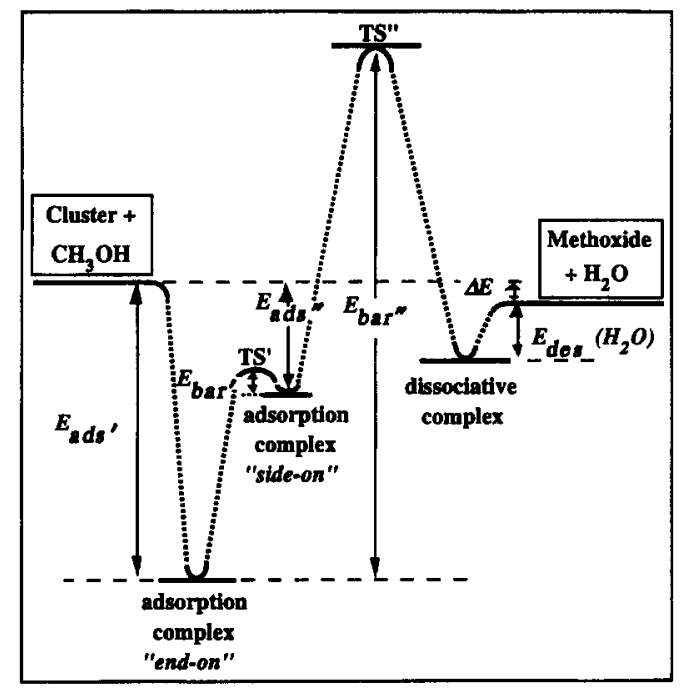

Fig. 5(b). Adsorption and desorption energies; activation energy with respect to "end-on" adsorption complex (TS') and activation energy for dissociation $\left(\mathrm{TS}^{\prime \prime}\right)[43]$.

In practice, deactivation of a catalyst often limits its application.

\section{CATALYSIS IN PERSPECTIVE}

\subsection{Introductory background}

Future developments in catalysis will be strongly influenced by changing societal needs, matched by autonomous scientific developments. One's view will strongly depend on our understanding how these two interact. In Fig. 7 we illustrate our view based on the science-technology double helix. As proposed by Casimir [48], technological advance can be considered as a spiral around the time vector. This leads to a technology spiral that is driven by needs of our society that produces new technology fed by new techniques from science. The science spiral is a second helix that delivers new methods or techniques to the technology spiral and can get a new direction, inspired by currently unsolved problems. The point made by this way of schematically representing progress in science and technology is that their interphase is crucial to both. The helix loops not only move toward each other but they also turn away from each other, a necessity for real scientific innovation. For this reason we separated in the previous section of this paper the industrial from scientific autonomous developments.

Interestingly, industrial catalysis as well as catalysis science seem to converge to a molecular approach. The industrial catalyst systems, especially homogeneous catalysts and also heterogeneous catalysts as the zeolites, become manipulable on a molecular level. Catalysis science, in heterogeneous catalysis and homogeneous catalysis, measures its scientific progress in terms of molecular understanding. The other important idea illustrated by Fig. 7 is the dynamic character of the interaction of science and technology. It is different from the well-known one-dimensional technological forecasting S-curve of technological advance vs time. According to this forecasting curve, early in a technological development fundamental science generates new inventions in a field with little knowledge. When knowledge increases developments are taken over by applied industrial research. According to the view expressed with the double helices of science and technology, science contributes to each stage of the technological S-curve. There is an ongoing feedback, also in applied research, between technological advance and knowledge, obtained by the use of state of the art techniques. An interesting illustration is provided for by the instrumentation of a current industrial catalysis laboratory. An extensive battery of modern sophisticated analytical, often spectroscopic, techniques is used by chemical engineers in charge of catalyst improvement or process research.

Another issue relates to the critical steps for technological advance. This is illustrated in the scheme shown in Fig. 8, called the chemistry hinges. Chemistry and Chemical Engineering is considered on a scale of increasing complexity. To the left are the classical academic disciplines, where innovation tends to be highly specialistic. At the right technology is located, considered for its role in our society. Here complex issues as transportation, environmental conservation, etc., are addressed. In the middle, one finds a heading called systems: as examples are mentioned the cell, catalytic reactor, etc.

A key to technological impact is the ability to translate broad societal demands into scientific or technological questions. So far, this task has been performed mainly in the large industrial or<smiles>[Z7]O[Te]1(O)(O)O[Tl]O[Te](=O)(=O)O1</smiles>

a

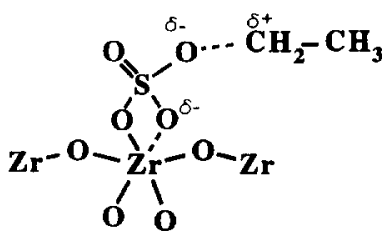

b

Fig. 6. The reaction of ethylene with sulfated zirconia (schematic) : (a) hydrogen-bonded sulfate proton; (b) activated sulfate ether by Lewis acidic $\mathrm{Zr}^{4+}$. 


\section{The Science-Technology Spiral}

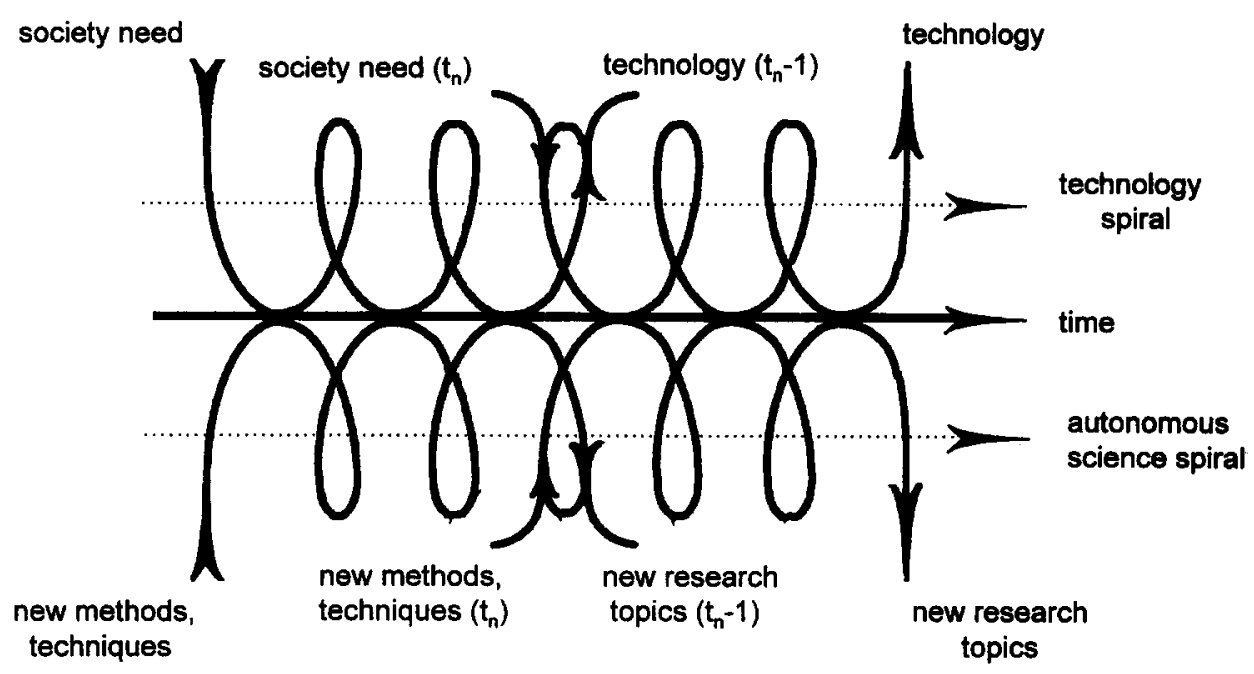

Fig. 7.

\section{Science-Technology Hinges in Chemistry}

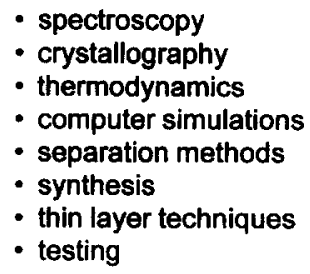

- membranes

- friction

- attachement

- fuel cel

- transistor

- catalytic reacton

- corrosion

- combustion

\section{- chemical process}

- communication

- transport

- environmental problems

- energy

- tools

hinge 1

hinge 2 chemical systems

Fig. 8. technology governmental research centers. It requires the possibility to integrate knowledge from subdisciplines to create usable systems. Crucial to technological advance is knowledge how to reduce system questions to disciplinary questions and to integrate the answers back into the complexity of the system. An interesting example of a system approach is provided for by the catalytic exhaust system for automotive emission control.

The noble metals dispersed on the applied catalyst, that is shaped such that pressure drop is prevented, are only active when there is no excess oxygen present in the exhaust gas. Hence, sensors are used, which via computer control, regulate the air/fuel ratio in the exhaust emission gas. Catalyst design is integrated with computer control to develop the catalytic automotive exhaust system.
Catalysis can be considered as an integrated science of many subdisciplines, whose progress depends on the understanding of the complexity of the complete catalytic reaction system.

Figure 9 illustrates this by considering the three main branches of catalysis: catalyst preparation, catalytic conversion and catalyst characterization, on three different levels. On a macroscopic level, catalyst characterization deals with surface area and morphology. Catalyst preparation concerns with shaping of catalysts and catalytic reactivity is the realm of reactor engineering. The mesoscopic level is the traditional level of academic catalytic chemists and engineers. Reactions are described in terms of conversion and selectivity and by kinetic equations. Pulse experiments and in situ studies of the catalytic surface are done to unravel structure-performance relationships. 


\section{Catalytic Prisma}

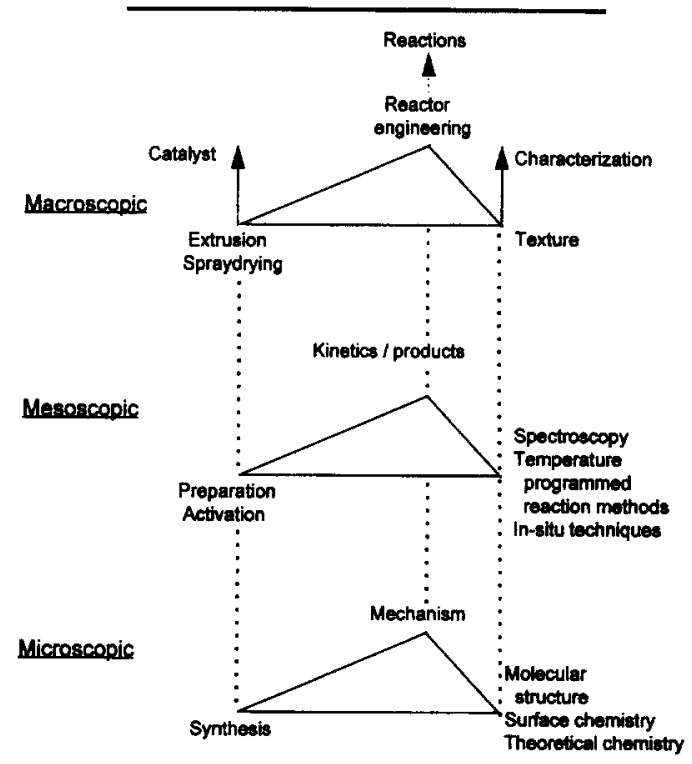

Fig. 9.

To prepare a catalyst the catalytically active component is often dispersed over a high surface area macroporous support. Catalyst preparation generated a strong need for catalyst characterization. An example of a classical technique is temperature-programmed reduction or reaction. Widely employed are vibrational spectroscopies as infrared or Raman spectroscopy. Electron microscopy, X-ray diffraction and XPS spectroscopy can also be considered as techniques mainly applied at the mesoscopic level. At the microscopic level the direct impact of modern chemistry and physical chemistry is largest. Catalyst preparation now is catalyst synthesis, using adapted organic synthesis strategies.

Model systems, in a surface-science-related approach, as single crystal surfaces or model catalysts on silicon wavers are used to study the reactivity of molecularly well-defined surfaces. Zeolites are also studied for this purpose. Catalyst characterization consists of spectroscopic studies aimed at the unravelling of catalyst synthesis processes and reaction mechanisms on a molecular level. Computational chemistry is used to support this activity.

\subsection{Trends in catalytic disciplines}

4.2.1. Catalyst synthesis. Clearly, in homogeneous catalysts reaction selectivity is controlled by the choice of ligands. A recent exciting development is the earlier-mentioned introduction of the early transitionmetal-based $\mathrm{Zr}$ of $\mathrm{Ti}$ catalysts that enable stereo-regular synthesis of polyolefin polymers. Their working is based on ligand choice. Another spectacular new development is seen in the polymerization of polyketone, from $\mathrm{CO}$ and ethylene [49]. Activity and selectivity of the homogeneous $\mathrm{Pd}$ system depends largely on the design of complex ligands. Both cases also exemplify the use of copromotors. In the first case alkoxy compounds play an important role that is currently little understood. In the latter case, choice of anions influences overall catalytic performance to a considerable extent.

An important issue is the separation of the product from the catalyst. When the catalyst is active enough no separation is required. This situation has been realized for polyolefin polymerization. However, in the production of intermediates or specialty chemicals, this is not always possible and catalyst immobilization can become an interesting option. The use of homogeneous catalysts may require ways to recover the catalysts that can also determine the choice of new ligands. Diphasic systems or liquid films on high surface area supported systems have been proposed. The latter serve to immobilize the liquid containing the homogeneous catalyst [50].

As long as conditions are mild, ligands will be stable and a strategy can be developed based on molecular control of the catalyst. Interesting systems can also be developed, where well-defined catalytically active centers become attached to an amorphous high surface support.

In case zeolites are chosen as supports, the high surface area microporous channel system provides an additional molecular variable for selectivity control. The ship in bottle [51] approach, that develops strategies for in situ synthesis of the catalytically active complex in the microcavities of the zeolite, is an interesting option.

Strategies for catalyst synthesis aim for:

- uniformity of catalyst site structure; a selectivity requirement

-optimum site accessibility; an activity requirement

- tunability of functionalities

- shape and strength compatible with mass and heat transport requirements

-flexibility, stability and price.

The examples mentioned previously mainly referred to the first point of this list. From a scientific point of view to develop a catalyst based on a predicted site requirement would imply ultimate success of a catalyst synthesis strategy. In biocatalysis, antibodies [52] appear to form a catalyst site based on shape recognition. Reaction with molecules that have a shape similar to the transition state of a desired reaction preshapes the antibody enzyme such that catalysts are generated selective for such a reaction.

Such a site shaping and shape recognition strategy has also been followed in zeolite synthesis. By choosing organic template molecules, with a shape close to expected transition states of desired conversion reaction, acidic zeolites with the preferred cavities have been synthesized useful to petrochemical reactions as catalytic dewaxing [53].

High surface area materials with uniform pore size distributions are now available as the MCM silica 
materials [54]. Uniform pore sizes between 20 and $60 \AA$ are available, tuned by choice of micel forming detergent to be used as gelling component. There is a wide range of sol-gel technologies available to synthesize the corresponding mixed oxide materials [55]. Alternative strategies to provide uniform microporous materials are based on the expansion of layered clays to provide pillared clays [56].

A completely different approach stems from semiconductor technology and surface science. The single crystal surfaces studied in surface science are well defined and uniform, but because of their low surface area cannot be used as such in practical catalysis. Using silica or aluminium wavers one can apply spin coating [57] techniques to prepare thin inorganic layers of catalytically active materials. It has been proposed [58] to apply microconductor mask and etch techniques to manufacture designed nanolayered catalysts. This would be an alternative to conventional approaches to coat a support surface with a catalytically active component.

Currently used impregnation techniques are not always suitable to prepare a uniform distribution of particles or clusters of the desired size or form. Coprecipitation with local control of $\mathrm{pH}$ and concentration, or reaction with catalyst site precursors and subsequent controlled activation are important alternative options.

Of major importance to nanoscale or molecularly controlled catalyst synthesis is the availability of adequate spectroscopic techniques not only to analyze and characterize the synthesized material, but also to follow catalyst synthesis in situ. Many spectroscopic techniques are now available. The use of synchrotron radiation to in situ follow aggregation and crystallization is an example [59].

With the increased understanding of reaction mechanism and chemical reactivity rational design of new or improved catalytic systems is becoming possible. The availability of new synthesis approaches and materials is expected to drive catalysis innovation to a significant extent.

In process research reactor engineering and catalyst development are closely related. Now many new developments occur where integration of the two subdisciplines appear to be even more essential. In the case reactions occur in solutions the desired catalyst architecture can sometimes be realized by the use of ceramic honeycombs [60]. Integrated catalyst design plays an important role in systems where catalysis is to be combined with separation or distillation. The desire to shift equilibria leads to the search for catalytic membrane processes [61], or to catalytic reactor concepts as catalytic distillation [62]. Another interesting example of the integration of separation with catalysis is the use of Courier Current Moving Bed Chromatographic Reactor [63].

4.2.2. Reactivity and kinetics. To the chemical engineer the use of kinetic equations is to predict conversion and selectivity of a reaction and to design a process. The chemical information is contained in the parameters as the effective rate constants and orders of the reaction. To formulate kinetic equations one has to propose a kinetic scheme, which can be considered as the mechanism of a reaction on a mesoscopic level. The study of kinetic parameters as a function of catalyst structure leads to structure-performance relationships. Many approximations can be used to derive kinetic equations from a kinetic scheme. Usually, kinetic parameters are assumed to be concentration-independent, often lump sum approximations are used or the kinetic expression is simply a power law in the concentrations (see Fig. 10).

As described in Section 3 on fundamental catalysis the surface chemical reactivity generally depends strongly on surface coverage. From a statistical point of view, mixing of adsorbed species is often highly nonideal. This may cause major difficulties in conventional kinetics modelling schemes, especially in practical situations when there is a concentration gradient in a catalyst pellet.

The use of model systems as the surface science single crystal approach has provided a scientific basis to the molecular understanding of surface reactions. For instance, it is well understood how the changes in surface overlayer composition relate with kinetic oscillations of the overall reaction rate. The structure and energetics of many adsorption complexes is now known in atomistic detail and their activation mechanisms have been understood.

Initially, there was a question how to relate information on surface reactivity obtained at ultra-high vacuum conditions to kinetic measurements at high pressures. This pressure gap problem has been resolved by the realization that the composition and structure of the surface layer will change with coverage. On the basis of this understanding elementary reaction rate constants obtained at "model" conditions can be used to predict overall kinetics at high pressure: An understanding of surface facetting and reconstruction which is a strong function of surface concentration is also essential. The understanding that the surface condition of the working catalyst can be a strong function of reaction conditions, results in a need for in situ spectroscopic techniques, that enables the study of the reacting surface as a function of reaction conditions. This is not limited to metal catalysts, but also applies to solid state materials as zeolites and reaction complexes in solution. The use of infrared spectroscopy [64] and advanced X-ray and EXAFS techniques [65] are examples of spectroscopic techniques applicable under in situ conditions.

Since a microscopic basis to chemical reactivity has been generated, computational chemistry becomes of use. Current quantum-chemical techniques and computational hardware facilities enable the accurate study of chemical models that are close to the atomistic models proposed for catalytically reactive sites. Ground state energies and vibrational spectra, accessible to experimental verification, can be predicted as 


\section{Chemical Engineering and Chemistry}

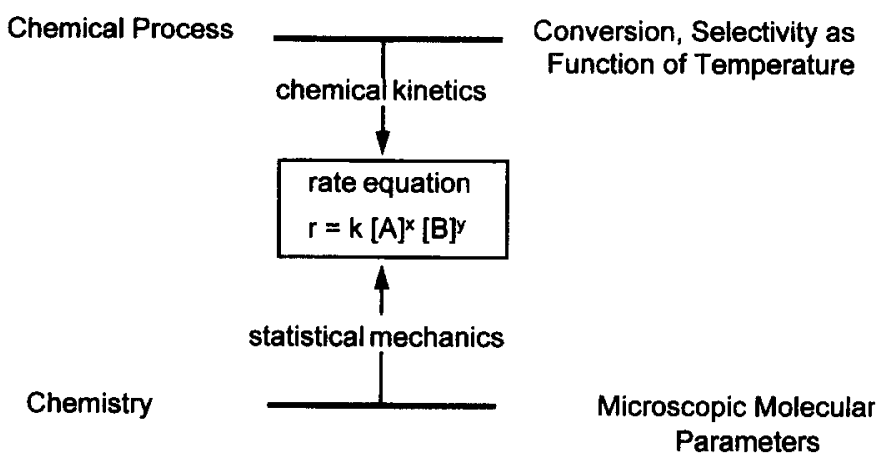

Fig. 10. The relation between kinetic and molecular chemical parameters.

well as transition states. Transition state reaction rate theory (rigorously valid for $E_{\text {act }}>5 \mathrm{kT}$ ) can be used to predict the preexponents of elementary reaction rate constants [39a]. Also the lateral interaction energies become accessible to calculation. Hence, the experimental as well as theoretical framework is in principle available to close the gap between the kinetics formulation on a mesoscopic level in terms of kinetic parameter by direct computation and measurement of elementary reaction rate constants and interaction parameters of the reacting molecules on a microscopic level. The microkinetics approach proposed by Dumesic [66] is a step towards this goal.

An important link between the knowledge of reaction steps of isolated molecules and the overall kinetic behavior is provided by the application of statistical mechanical techniques [67], as the Monte Carlo methods we discussed before [10].

Essential for the formulation of proper mechanistic steps in the catalytic reaction cycle is direct information on the actual intermediates of the chemical conversion steps. Trapping of intermediates, isotope labelling and transient experiments are important approaches used to unravel mechanism. Again theory can be used to transform this information into parameters of elementary reaction rate constants.

Clearly, the marriage of the new molecular insights, as provided by physical model approaches and in situ measurements of working practical catalytic systems, is one of the most exciting current developments. Computational quantum-chemical and statistical techniques are the vehicles closing the microscopic and macroscopic sciences gap.

The modern approach to catalytic reaction modelling will require the following strategy.

-determination of overall intrinsic kinetics of a catalytic system.

-in situ determination of catalyst composition, structure and reaction intermediates; establish mechanism. -measure elementary rate constants of essential reaction steps on model system under well-defined model conditions; transient kinetics; structure-function relationships.

- compute interaction energies and reaction barriers difficult to obtain by experiment; spectroscopic measurements for verification.

- simulate overall kinetics of the reaction using statistical mechanical techniques; develop effective kinetic expressions.

So far, only the $\mathrm{CO}$ oxidation reaction [68] catalyzed by $\mathrm{Pt}$ and ammonia synthesis [69] have been studied with a level of detail as proposed by this strategy.

It may be worthwhile to remember the very different time scales of the elementary processes that are part of the catalytic reaction cycle, mentioned in Section 3. On the time scale of the slow overall catalytic reaction, the faster processes can be considered equilibrated. This is implicit to the proposed kinetics modelling strategy. The fast elementary processes provide the parameters that are input to the slower elementary processes.

Measurements on short time scales are often useful to provide energetic or entropic parameters of use to the overall modelling process. The characteristic length scale of the catalytic reaction cycle is the size of surface ensembles, typically a few surface atoms.

The concentration on different reaction sites may also be synchronized by nonideal surface ordering effects extending over a distance typical of the correlation length of an ordered surface layer. Surface- or gas-phase transport can lead to mesoscopic spatiotemporal patterns. In the case of bifunctional catalysis several sites may be involved linked by the gas phase, bulk or surface transport processes.

\section{CATALYSIS IN PRACTICE}

The reduced energy consumption, increased yields and high selectivities obtainable by catalytic processes will ensure a continued search for new or improved 
catalysis. As mentioned in the Introduction industrial catalytic research has not only resulted in improved efficiencies of many existing large-scale processes, but has generated over the years many new processes. A development that continues at the present time and is not foreseen to stop in the near future. The latter is due to the strong influence of changing societal demands for chemical processes. Currently, the society needs environmentally clean processes with clean waste streams and processes that regenerate raw materials from waste products. In addition, there is a long list of reactions that are desirable [70], but for which no catalytic system has yet been found. Examples of such reactions are direct oxidation of propylene to propylene epoxide or oxidation of methane to methanol. Other examples are the direct oxidation of $\mathrm{N}_{2}$ to nitrate, or low-temperature hydrocarbon oxidation. Sometimes selective conversion is limited because of rapid consecutive reactions. A breakthrough is the recent demonstration by Schmidt [71] of selective $\mathrm{CH}_{4}$ oxidation to synthesis gas at high temperature, when short contact times are used. Another reason that mentioned reactions are nonselective or have low rates stems from the incompatibilities of the conditions needed to activate a reaction molecule from the conditions optimum for selective product formation.

As a consequence in practice sometimes processes are not performed in one single step, but catalyst regeneration and product formation step alternate. Conditions can be optimized for selective surface reactions, separate from the conditions needed to activate the reactant. In selective oxidation processes often the reoxidation of the catalyst is separated from the reaction of oxidized catalyst with reactant. The butane oxidation process [72] mentioned before, is an example where the process is overall catalytic, but the actual reaction sequence occurs in two steps. Selective butane oxidation proceeds on the oxidized catalyst, with oxygen absent from the gas phase. Catalyst regeneration by oxidation occurs in a separate step. The catalyst recycle system used generates special catalyst strength and shape requirements. Use of the catalytic reagents appears to be a very promising approach to environmentally beneficial fine chemical production [73]. The catalytic material is considered as a selective reagent. Reactor operation under transient conditions is also a way to optimize conditions suitable for different steps. Alternating flow incineration processes have been developed to optimize energy consumption [74].

Catalytic combustion lowers oxidation temperatures and hence reduces $\mathrm{NO}_{x}$ emission, which is of importance to turbine applications. For applications in combustion technology ceramic materials are necessary as catalyst material, stable with respect to sintering at severe conditions. Here solid state chemistry has a challenging task.

The need for environmentally beneficial catalytic engineering translates into four approaches: -treating of waste streams: removal of molecules as $\mathrm{NO}, \mathrm{SO}_{2}, \mathrm{H}_{2} \mathrm{~S}, \mathrm{NO}_{3}^{2-}, \mathrm{NH}_{3}$ from gas or water;

-clean and efficient processes: organic chemicals production without salt; replacement of $\mathrm{HF}$ or $\mathrm{H}_{2} \mathrm{SO}_{4}$, catalytic combustion; high temperature selective oxidation fuel cells

一new products: stereo-selective production of pharmaceuticals and agrochemicals, new oil products and energy carriers, replacements of CFCs

- recycling: cracking of polymers, degradation of chlorine containing organics.

As already mentioned in the introduction section a wide variety of catalytic options exist to find solutions. Improved catalyst formulations and alternative process options will also be developed.

There is a large database of known catalytic conversion reactions and their catalysts, ample understanding of the essential mechanistic steps as well as the factors that cause deactivation of the catalysts. This knowledge and the advanced status of catalyst characterization methods will reduce development time for process improvement and new processes significantly.

\section{REFERENCES}

[1] Mittasch, A., 1951, Geschichte der Ammoniak Synthese. VCH, Weinheim.

[2] Froment, G.F. and Bischoff, K.B., 1979, Chemical Reactor Analysis and Design. Wiley, New York.

[3] Thomas, J.M., 1988, Turning points in catalysis. Angew. Chem. Inst. Ed. Engr. 27, 1673.

[4] Brunauer, S., Emmett, P.H. and Teller, E., 1988, Adsorption of gases in multimolecular layers. $\mathrm{J} . \mathrm{Am}$. Chem. Soc. 60, 309.

[5] Langmuir, I., 1916, The constitution and fundamental properties of solids and liquids. J. Am. Chem. Soc. 38, 2221.

[6] Somorjai, G.A., 1981, Chemistry in Two Dimensions. Cornell Univ. Press, Cornell.

[7] (a) Ertl, G., Norton, P.R. and Rüstig, J., 1982, Kinetic oscillations in the platinum-catalyzed oxidation of cobalt. Phys. Rev. Lett. 49, 177.

(b) Cox, M.P., Ertl, G. and Imbihl, R., Spatial selforganization of surface structure during an oscillating catalytic reaction. Phy. Rev. Lett. 54, 1725.

(c) Imbihl, R., Cox, M.P. and Ertl, G., 1986, Kinetic oscillations in the catalytic carbon monoxide oxidation on platinum (100): experiments. J. chem. Phys. 84, 3519.

[8] Thomas, J.M., 1992, Solid acid catalysts. Sci. Am. 266, 112.

[9] (a) Hoffmann, R., 1988, Solids and Surfaces. A Chemist's View of Bonding in Extended Structures. VCH, Weinheim.

(b) van Santen, R.A., 1991, Theoretical Heterogeneous Catalysis. Word Scientific, Singapore.

[10] (a) Kang, H.Ch. and Weinberg, W.H., 1994, Kinetic modeling of surfaces rate processes. Surf. Sci. 299, 755. (b) Lombardo, S.J. and Bell, A. T., 1991, A review of theoretical models of adsorption, diffusion, desorption, and reaction of gases on metal surfaces. Surf. Sci. Rep. 13,1 .

(c) Zhdanov, V.P., 1991, Elementary Physicochemical Processes on Solid Surfaces, Plenum, New York.

[11] Sabatier, P., 1923, Catalysis in Organic Chemistry. The Library Press.

[12] Ipatieff, V., 1936, Catalytic Reactions at High Pressures, and Temperatures. MacMillan, New York. 
[13] Thomas, J.M., 1991, Michael Faraday and the Royal Institutions, The Genius of Man and Place. Adam Hilger, Bristol.

[14] Balandin, A.A., 1958, The nature of active centers and the kinetics of catalytic dehydrogenation. Adv. Catal. $10,96$.

[15] (a) Smidt, J., Hafner, W., Jira, R., Sedlmeyer, I., Sieber, R., Rüttinger, R. and Kojer, H., 1959, Katalytische Umzetzungen von olefinen an Platinmetall-verbindingen. Angew. Chem. 71, 176.

(b) Moiseev, I.I., Vargaffik, M.N. and Sardin, Ya. K. 1960, Alkene oxidation reactions. Dokl. Akad. Nauk USSR 130, 820; 133, 377.

(c) Moiseev, I.I., Vargaftik, M.N. and Syrhim, Ya.K., 1960, About the mechanism of the reaction between palladium and alkenes in hydroxyl containing solvents. Dokl. Akad. Nauk USSR 133, 377.

[16] (a) Reppe, W., 1949, Neue entwicklungen auf den Gebiet der Chemie des Acetylens und Kohlenoxyds. Springer, Berlin.

(b) Knowles, W.S., Sabacky, M.J. and Vinegard, B.D., 1974, Adv. Chem. Ser. 132, 274.

[17] Kaminsky, W., Kuelper, K., Brintzinger, H.H. and Wild, F.R.W.P., 1985, Polymerization of propene and butene with a chiral zirconocene and methylaluminoxane as cocatalyst. Angew. Chem. Inst. Ed. Engr. $97,507$.

[18] Quadbeck-Seeger, H.J., 1990, Chemistry for the future-state of art and perspectives. Angew. Chem. Inst. Ed. Engr. 29, 1177.

[19] (a) Fischer, F. and Tropsch, M., 1926, Úber die direckte Synthese von Erdöl-Kohlenwasserstoffen bei gewöhnlichem Druck. Berichte Deutschen Chem. Gesellschaft. 59,830 .

(b) Fischer, F. and Tropsch, H., 1926, Uber die Reduction und Hydrierung des Kohlenoxyds. BrennstoffChemie. 7, 97.

[20] Natta, G. and Pasquon, I., 1959, The kinetics of the stereospecific polymerization of $\alpha$-olefins. Adv. Catal. 11,1 .

[21] (a) Olah, G.A., 1973, Stable carbocations. 138. Carbocations and electrophilic reactions. Angew. Chem. 85, 183.

(b) Olah, G.A., 1972, Stable carbocations. CXVIII. General concept and structure of carbocations based on differentiation of trivalent (classical) carbenium ions from three-center bound penta- of tetracoordinated (nonclassical) carbenium ions. Role of carbocations in electrophilic reactions. J. Am. Chem. Soc. 94, 808

(c) Brouwer, D.M. and Hogeveen, H., 1972, Electrophilic substitutions at alkenes and in alkylcarbonium ions. Prog. Phys. Org. Chem. 9, 179.

[22] Grasselli, R.K. and Burrington, J.D., 1981, Selective oxidation and ammoxidation of propylene by heterogeneous catalysis. Adv. Catal. 30, 133

[23] van Santen, R.A. and Kuipers, H.P.C.E., 1987, The mechanism of ethylene epoxidation. Adv. Catal. 35, 265.

[24] Roth, J.F., Craddock, J.H., Hershman, A. and Paulik, F.E., 1971, Low-pressure process for acetic acid via carbonylation. Chem. Tech. 600 .

[25] (a) Taylor, R.C., 1987, in Catalysis and Automotive Pollution Control (Edited by A. Crucq and A. Frennet). Elsevier, Amsterdam.

(b) Bosch, H. and Janssen, F., 1988, Catalytic reduction of nitrogen oxides. A review on the fundamentals and technology. Catal. Today 2, 369.

[26] Iwamoto, M., 1994, Zeolites in environmental catalysis, in Zeolites and Related Microporous Materials (Edited by J. Weitkamp, H.G. Karge, H. Pfeifer, W. Holderich). Stud. Surf. Sci. Catal. 84, 1395.

[27] Belussi, G. and Rigutto, M.S., 1994, Metal ions associated to the molecular sieve framework: possible catalytic oxidation states, in Advanced Zeolite Science and Applications (Edited by J.C. Jansen, M. Stöcher,
H.G. Karge and J. Weitkamp). Stud. Surf. Sci Catal. 85, 177.

[28] Manzer, L.E. and Rao, V.N.M., 1993, Catalytic synthesis of chlorofluorcarbon alternatives. Adv. Catal. 39, 329.

[29] Osborn, J.A., Jardine, F.N., Young, J.F. and Wilkinson, G., 1966, The preparation and properties of tris (triphenyl-phosphine) halogenorhodium (1) and some reactions thereof including catalytic homogeneous hydrogenation of olefins and acetylenes and their derivates. J. Chem. Soc. (A) 1711.

[30] Topsøe, H., Boudart, M., Nørskov, J.R. (eds) Frontiers in catalysis: Ammonia Synthesis and beyond. Topics Catal. 1.

[31] Somorjai, G.A., 1992, Correlations and differences between homogeneous and heterogeneous catalysis. A surface science view. in Perspectives in Catalysis (Edited by J.M. Thomas and K.I. Zamaraev), p. 147. Blackwell, Oxford.

[32] Nørskov, J., 1990, Chemisorption on metal surfaces. Rep. Prog. Phys. 53, 1253.

[33] Somorjai, G.A., 1994, The surface science of heterogeneous catalysis. Surf. Sci. 299, 849.

[34] Biloen, P. and Sachtler, W.M.H., 1981, Mechanism of hydrocarbon synthesis over Fischer-Tropsch catalysts. Adv. Catal. 30, 165

[35] Koerts, T., Deelen, M.J.A.G. and van Santen, R.A., 1992, Hydrocarbon formation from methane by a lowtemperature two-step reaction sequence. J. Catal. 138, 101.

[36] Besenbacher, F., Sprunger, P.T., Ruan, L., Olesen, L., Stensgaard, I. and Logsgaard, E., 1994, Direct observations of changes in surface structures by scanning tunneling microscopy. Topics Catal. 1, 325.

[37] (a) Roberts, M.W., 1994, Chemisorption and reactions at metal surfaces. Surf. Sci. 299, 769.

(b) Carley, A.F., Davies, P.R., Roberts, M.W. and Vincent, D., 1994, Oxygen sites active in $\mathrm{H}$-abstraction at a $\mathrm{Cu}(110)-\mathrm{O}$ surface: comparison of a Monte Carlo simulation with inside formation studied by XPS and VEELS. Topics Catal. 1, 35.

[38] Nieuwenhuys, B.E., 1983, Adsorption and reactions of carbon monoxide, nitric oxide, hydrogen, and oxygen on Group VIII metal surfaces. Surf. Sci. 126, 307. Nieuwenhuys, B.E., Siera, J., Tanaka, K.I. and Hirano, $\mathrm{H}$. 1994, Differences in behaviour of $\mathrm{Pt}, \mathrm{Rh}$ and $\mathrm{Pt}-\mathrm{Th}$ alloy surfaces towards NO reduction, in Environmental Catalysis (Edited by J.N. Armor), ACS Symp. Ser. 552 , pp. 140-156. American Chemical Society, Washington, DC

[39] (a) van Santen, R.A. and Neurock, M., Concepts in theoretical heterogeneous catalytic reactivity, Catal. Rev. 1995 (in press)

(b) Neurock, M. and van Santen, R.A., 1994, Theory of carbon-sulfur bond activation by small metal sulfide particles. J. Am. Chem. Soc. 116, 4427.

[40] (a) Iwasawa, Y., 1993, The effects of coadsorbates on the behaviour of surface species and sites in catalysis by means of EXAFS and FTIR, in Elementary Reaction Steps in Heterogeneous Catalysis (Edited by R.W. Joyner and R.A. van Santen), p. 287. Kluwer, Dordretcht (b) Oniski, H., Aruga, T. and Iwasawa, Y., 1994, Switchover of reaction paths in the catalytic decompositions of formic acid on $\mathrm{TiO}_{2}(110)$ surface. $J$. Catal 146, 557.

[41] Frelink, T., Visscher, W.H.M. and van Veen, J.A.R., 1994, The effect of $\mathrm{Sn}$ on $\mathrm{Pt} / \mathrm{C}$ catalysts for the methanol electro-oxidation. Electrochim. Acta 39, 1871.

[42] (a) van Santen, R.A. and Kramer, G.J., 1995, Reactivity theory of zerolitic Brensted acidic sites. Chem. Rev. 637.

(b) Kazansky, V.B., 1991, The nature of adsorbed carbenium ions as active intermediates in catalysis by solid acids. Acc. Chem. Res. 24, 379. 
[43] Blaszkowski, S. and van Santen, R.A., 1995, Density functional theory calculations of the activation of methanol by a Brønsted zeolitic proton. J. phys. Chem. 99, 11728

[44] (a) Jin, T., Yamaguchi, T., Tanabe, K., 1986, Mechanism of acidity generation on sulfur-promoted metal oxides. J. phys. Chem. 90, 4794.

(b) Arata, K., 1990, Solid superacids. Adv. Catal. 37, 165. (c) Adeeva, V., de Haan, J.W., Jänchen, J., Lei, G.L., Schüneman, V., Ven, J.L.M. v.d., Sachtler, W.M.H. and van Santen, R.A., 1995, Acid sites in sulfated and metalpromoted zirconium dioxide catalysts. J. Catal. 151, 364.

[45] (a) Derouane, E.G., 1986, Shape selectivity in catalysis by zeolites: the nest effect. J. Catal. 100, 541 . (b) Derouane, E.G., André, J.M. and Lucas, A.A., 1988, Surface curvature effects in physisorption and catalysis by microporous solids and molecular sieves. $J$. Catal. $110,58$.

[46] Jacobs, P.A. and Martens, J.A., 1991, Introduction to acid catalysis with zeolites in hydrocarbon reactions, in Introduction to Zeolite Science and Practice (Edited by H. van Bekkum, E.M. Flanigan and J.C. Jansen). Stud. Surf. Sci. Catal. 58, 445 .

[47] Menon, P.G., 1994, Diagnosis of industrial catalyst deactivation by surface characterization techniques. Chem. Rev. 94, 1021.

[48] Casimir, H.B.G., 1993, Haphazard Reality: Half a Century of Science. Harper Row, New York.

[49] Drent, E., van Broekhoven, J.A.M. and Doyle, M.J., 1991, Efficient palladium catalysts for the copolymerization of carbon monoxide with olefins to produce perfectly alternating polyketones. J. Organomet. Chem. 417, 235.

[50] Wan, K.T. and Davis, M.E., 1994, Design and synthesis of a heterogeneous asymmetric catalyst. Nature $\mathbf{3 7 0}$, 449.

[51] Sachtler, W.M.H. and Zhang, Z., 1993, Zeolitesupported transition metal catalysts. Adv. Catal. 39, 129.

[52] (a) Tramontano, A., Janda, K.D. and Lerner, R.A., 1986, Catalytic antibodies. Science 234, 1566

(b) Pollack, S.J., Jacobs, J.W., Schulz, P.G., 1986, Selective chemical catalysis by an antibody. Science 234, 1570 .

[53] Harris, T.V. and Zones, S.I., 1994, A study of guest/host energetics for the synthesis of cage structures NON and CHA, in Zeolites and Related Microporous Materials, State of the Art (Edited by J. Weitkamp, H.G. Karge and H. Pfeifer, Hölderich). Stud. Surf. Sci. Catal. 84, 29.

[54] (a) Beck, J.S., Vartuli, J.C., Roth, W.J., Leonowicz, M.E., Kresge, C.T., Schmitt, K.D., Chu, C.T.W., Olson, D.H., Sheppard, E.W., et al., 1992, A new family of mesoporous molecular sieves prepared with liquid crystal templates. J. Am. Chem. Soc. 114, 10834.

(b) Livage, J., 1994, Sol-gel chemistry and molecular sieve synthesis, in Advanced Zeolite Science and Applications (Edited by J.C. Jansen, M. Stöcker, H.G. Karge and J. Weitkamp). Stud. Surf. Sci. Catal. 85, 1.

[55] Thomas, J.M., Theocharis, C.R. and Charis, R., 1992 Catalysis with clays and their pillared variants, in Perspectives in Catalysis (Edited by J.M. Thomas and K.I. Zamaraev), p. 465. Blackwell, Oxford.

[56] (a) Mortland, M.M. and Pinnavaia, T.J., 1971, Formation of copper (II) arene complexes on the interlamellar surfaces of montmorillonite. Phys. Sci. 229, 75.

(b) Tzou, M.S. and Pinnavaia, T.J., 1988, Chromia pillared clays. Catal. Today 2, 243.

(c) Figueras, F., 1988, Pillared clays as catalysts. Catal. Rev. Sci. Engng 30, 457.

[57] van Hardeveld, R.M., Gunter, P.L.J., van IJzendoorn, L.J., Wieldraaijer, W., Kuipers, E.W. and Niemantsverdriet, J.W., 1995, Deposition of inorganic salts from solution on flat substrates by spin coating: theory, quantification and application to model catalysts. Appl. Surf. Sci. 84, 339.

[58] Ribeiro, F.H. and Somorjai, G.A., 1994, The fabrication of "high-technology" catalysts. Recl. Trav. Chim. Pays-Bas 113, 419.

[59] Pantos, E., West, J.B., Dokter, W.H., van Garderen, H.F., Beelen, T.A.M. and van Santen, R.A., 1994, Growth and aging phenomena in silica gels. J. Sol-Gel Sci. Technol. 2, 273 .

[60] Cybulski, A. and Moulijn, J.A., 1994, Monoliths in heterogeneous catalysis. Catal. Rev, 36, 2.

[61] Saracco, G. and Specchia, V., 1994, Catalytic inorganic-membrane reactors: present experience and future opportunities. Catal. Rev. Sci. Engng 36, 305. Harold, M.P., Lee, C., Burggraef, A.J., Keizer, K., Zaspalis, V.T. and de Lange, R.S.A. 1994, Catalysis with inorganic membranes. Mater. Res. Soc. Bull. 19, 34.

[62] Schmith, L.D., Jones, E.M. and Hearn, D., 1991, AIChE Spring meeting, Houston; USP. 4, 307, 254; USP $4,443,559$.

[63] (a) Tonkovich, A.L., Carr, R.W. and Aris, R., 1993, Enhanced ethylene yields from methane oxidative coupling by means of a separative chemical reactor. Science 262, 221.

(b) Ray, A., Tonkovich, A.L., Aris, R. and Carr, R.W., 1990, The simulated countercurrent moving bed chromatographic reactor. Chem. Engng Sci. 45, 2431.

[64] Knözinger, H. and Ratnasamy, P., 1978, Catalytic aluminas: surface models and characterization of surfaces sites. Catal. Rev. -Sci. Engng 17, 31.

[65] (a) Sankar, G., Wright, P.A., Natarajan, S., Thomas, J.M., Greaves, G.N., Dent, A.J., Dobson, B.R., Ramsedale, C.A. and Thomas, R.H., 1993, Combined QuEXAFS-XRD: a new technique in high-temperature materials chemistry; an illustrative in situ study of the zinc oxide-enhanced solid state production of cordierite from a precursor zeolite. J. Prep. Chem. $97,9550$. (b) Thomas, J.M. and Greaves, G.N., 1993, Combined EXAFS and XRD for the in situ structural elucidation of solid catalysts under operating conditions. Catal. Lett. 20, 337.

(c) Clausen, B.S., Graabaek, L., Steffensen, G., Hansen, P.L. and Topser, H., 1993, A combined QEXAFS/ XRD method for online, in situ studies of catalysts: examples of dynamic measurements of copper-based methanol catalysts. Catal. Lett. 20, 23.

(d) Koningsberger, D.C. and Prins, R. (eds), 1988, $X$ Ray Absorption, Principles, Applications, Techniques of EXAFS, SEXAFS and XANES. Chemical Analysis, Ser. (Edited by J.D. Winefordner). Wiley-Interscience, New York.

[66] Dumesic, J.A., Rudd, D.F., Aparicio, L.M., Rekoske, J.E. and Trevino, A.A., 1993, The microkinetics of Heterogeneous Catalysis. American Chemical Society, New York.

[67] van Santen, R.A. and Niemantsverdriet, J.W., 1995, Chemical Kinetics and Catalysis. Plenum, New York.

[68] (a) Engel, T. and Ertl, G., 1979, Elementary steps in the catalytic oxidation of carbon monoxide on platinum metals. Adv. Catal. 28, 1.

(b) Sault, A.G. and Goodman, D.W., 1989, Model studies of surface catalyzed reactions. Adv. Chem. Phys. 76, 153.

[69] Jennings, J.R., (ed), 1991, Catalytic Ammonia Synthesis, Fundamentals and Practice. Plenum, New York.

[70] Whitesides, G.M., 1990, Wohin geht die Chemie in der nächsten zwanzig Jahren. Angew. Chem. 102, 1247 .

[71] Schmidt, L.D. and Hickman, P.A., Production of syngas by direct catalytic oxidation of methane. Science 59 , 343 . 
[72] Centi, G., Trifiro, F., Ebner, J.R. and Franchatti, V.M., 1988. Mechanistic aspects of maleic anhydride synthesis from C4 hydrocarbons over phosphorus vanadium oxide. Chem. Rev. 88, 55.

[73] Laszlo, P., 1986, Catalysis of organic reactions by inorganic solids. Acc. Chem. Res. 19, 121.
[74] (a) Boreskov, G.K. and Matros, Yu. Sh, 1983, Unsteady-state performance of heterogeneous catalytic reactions. Catal. Rev. -Sci. Engng 25, 551.

(b) Matros, Yu. Sh., 1990, Catalytic Process Under Unsteady State Condition. VNU Science Press, Zeist, The Netherlands. 